\title{
Giant Cell Arteritis: Visual Loss Is Our Major Concern
}
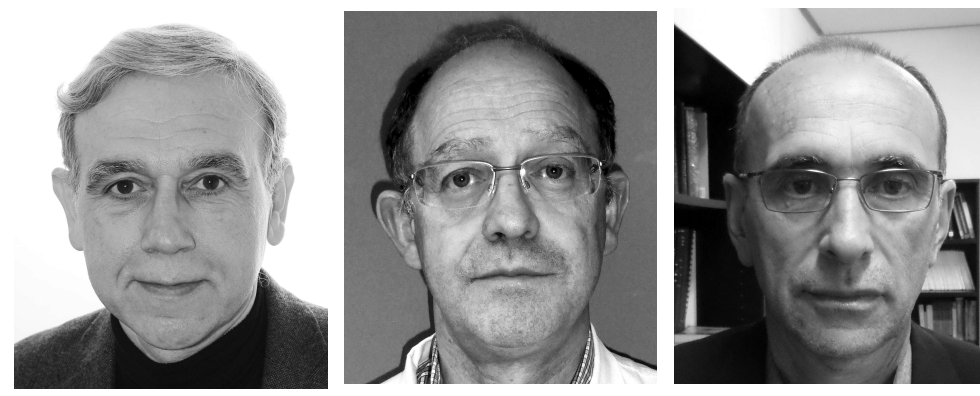

Giant cell arteritis (GCA) is the most common vasculitis in Western countries among individuals 50 years and older ${ }^{1}$. This medium and large-vessel granulomatous vasculitis typically affects the extracranial branches of the carotid artery ${ }^{1}$. Common features of the disease such as headache or jaw claudication are the result of vasculitic involvement of arteries derived from the external carotid artery. However, visual manifestations, including visual loss - the most feared complications of this vasculitis - are generally due to the arteritic damage affecting the ophthalmic branches of the internal carotid artery ${ }^{2}$.

The most common ophthalmic manifestation of GCA is anterior ischemic optic neuropathy, which is caused by interruption of blood flow in the posterior ciliary arteries to the optic nerve head. The clinical picture is described as sudden painless loss of vision ${ }^{3}$. Visual loss may present as a mist in all or part of the visual field and evolve within 24 to 48 hours to total blindness. Unilateral visual loss may be initially unnoticed by the patient until, by chance, the unaffected eye is covered. One eye is affected first, but involvement of the other eye in untreated patients may occur 1 to 10 days after the initial event ${ }^{4}$. In the acute phase of anterior ischemic optic neuropathy, the optic disc is pale and swollen, but the retina is almost normal. Afterward, optic nerve atrophy associated with optic disc cupping is observed. Less commonly, visual loss is caused by central retinal artery occlusion, ischemic retrobulbar neuropathy or occipital infarction in the context of a stroke involving the vertebrobasilar territory ${ }^{2}$. When the arteritic process involves the central retinal artery leading to retinal stroke, the retina is damaged primarily and it appears greyish and swollen, and a contrasting red zone can be observed in the macula, the so-called "cherry red spot."

In this issue of The Journal, Saleh, et al report data on visual complications in biopsy-proven GCA patients from the area of Skåne, the southernmost administrative county of Sweden ${ }^{5}$.

The incidence rate of visual complications in this population-based study was 3 times higher in patients with biopsy-proven GCA than in reference people without GCA from the background population ${ }^{5}$. However, the frequency of visual ischemic complications, in particular visual loss, was lower than that reported in former population-based studies. In the area of Skåne, visual complications occurred in $10 \%$ of the patients with biopsy-proven GCA ( 85 of 840 cases). Only 18 (21\%) of the 85 patients who had visual complications experienced complete visual loss ${ }^{5}$. It means that in the whole series of 840 patients with GCA, the frequency of permanent visual loss was $2 \%$. Population-based studies published in the last decade described a higher frequency of visual complications ${ }^{6,7}$. In this regard, visual manifestations developed in $41(30.1 \%)$, and partial or total visual loss in $26(19.1 \%)$ of 136 patients with biopsy-proven GCA diagnosed in Reggio Emilia (Italy) between 1986 and $2002^{6}$. Visual ischemic manifestations and irreversible visual loss were observed in 57 (22.4\%) and 32 $(12.5 \%)$ of the 255 biopsy-proven GCA cases diagnosed in Lugo (northwest Spain) between 1981 and $2005^{7}$. It was noteworthy that a negative trend, manifested by a statistically significant progressive decline in the number of patients with visual ischemic manifestations over the 25 -year period of study, was observed in Lugo ${ }^{7}$. A progressive decrease in the number of patients with biopsy-proven GCA who had irreversible visual loss was also found over the same period of study ${ }^{7}$. Because of that, a significant trend for decline in the frequency of permanent visual loss was also observed ${ }^{7}$. Figure 1 displays the decreasing trend in the proportion of patients with GCA having permanent visual loss in Lugo from 1981 to 2008. In accordance with Saleh, et al ${ }^{5}$, we feel that higher physician awareness of GCA may be a plausible explanation for the decrease in the frequency of visual ischemic complications in general, and specifically of permanent visual loss in different parts of the world.

A second point of interest addressed by Saleh, et al was the potential influence of predisposing factors for visual

\section{See Visual complications in GCA, page 1559}




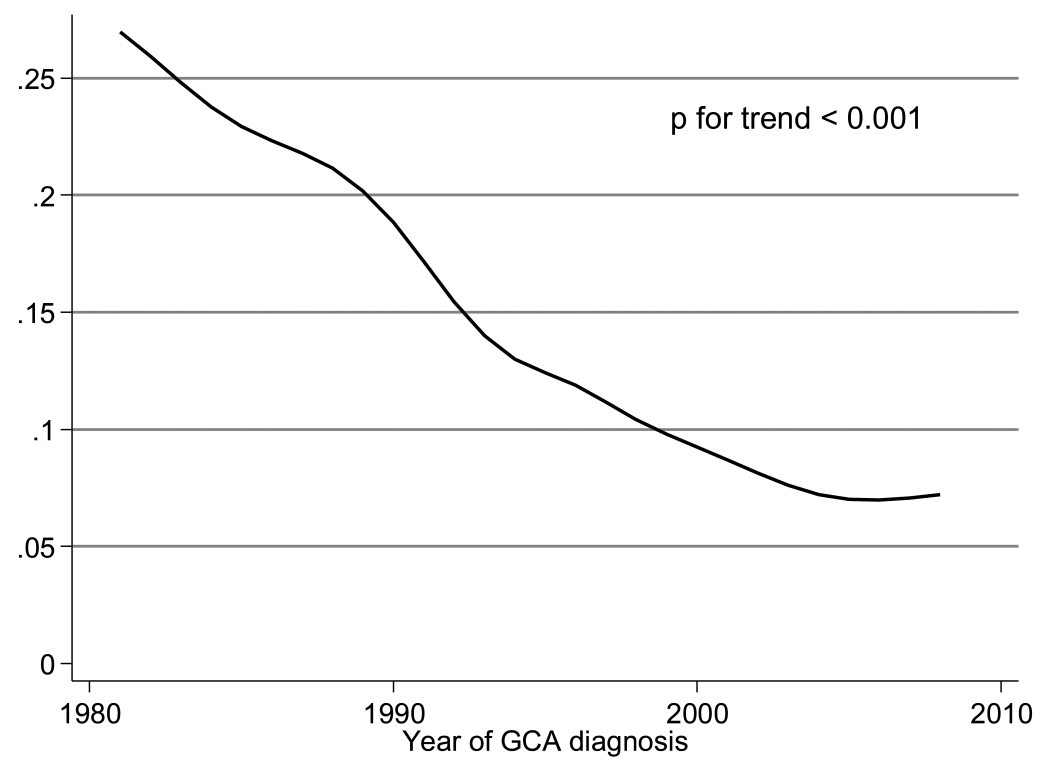

Figure 1. Frequency of permanent visual loss in patients with biopsy-proven GCA from Lugo (northwest Spain) on reappraisal. There was a decreasing trend in the proportion of patients with GCA with permanent visual loss in the Lugo cohort from 1981 to 2008. Results were smoothed using local spline functions. GCA: giant cell arteritis.

ischemic complications in $\mathrm{GCA}^{5}$. Traditional cardiovascular risk factors, in particular the presence of hypertension (HTN) before the onset of the vasculitis, were previously reported to be risk factors for severe ischemic complications in patients with biopsy-proven $\mathrm{GCA}^{8}$. In keeping with that, Saleh, et al disclosed an association between antihypertensive therapies, in particular with $\beta$-adrenergic inhibitors, at the time of disease diagnosis and the development of visual complications in biopsy-proven GCA in southern Sweden ${ }^{5}$. The association may be the result of a confounding by indication effect. Antihypertensive drugs were more commonly given to patients who had an underlying vascular disease before the onset of $\mathrm{GCA}^{5}$. Therefore, the presence of arteriopathy due to HTN could predispose to more severe ischemic events including visual complications of GCA.

Southern Swedish patients with GCA who experienced visual complications had significantly lower C-reactive protein (CRP) levels at disease diagnosis than those without visual complications ${ }^{5}$. However, to our surprise, no association between erythrocyte sedimentation rate (ESR) and ischemic events was found in this population ${ }^{5}$. It sounds odd because we observed high correlations among ESR, CRP, hemoglobin, and platelet count in biopsy-proven GCA cases from northwest Spain ${ }^{9}$. In this region, ESR levels at the time of disease diagnosis were predictors of irreversible visual $\operatorname{loss}^{10}$. An increased risk of visual ischemic manifestations and especially of permanent visual loss was observed in Lugo patients presenting with an ESR ranging between 70 and 100 $\mathrm{mm} / \mathrm{h}^{10}$. In agreement with our findings, Salvarani, et al reported ESR values at diagnosis that were significantly lower in patients with biopsy-proven GCA from Reggio Emilia who had permanent visual loss ${ }^{6}$. By multivariate logistic regression, the absence of high levels of ESR ( $>96$ $\mathrm{mm} / \mathrm{h}$ ) at the time of disease diagnosis was the best predictor for development of permanent visual loss ${ }^{6}$. A recent study of this group also indicates that, besides calcifications at temporal artery biopsy, lower CRP values are also predictors for development of permanent visual loss ${ }^{11}$. Cid, et al also found that the mean ESR was significantly reduced in their patients with irreversible cranial ischemic complications compared with the rest of the patients with biopsy-proven $\mathrm{GCA}^{12}$. The same group provided data supporting the idea that inflammation-induced angiogenic activity could counteract the risk of ischemic complications in patients with $\mathrm{GCA}^{13}$. Patients with a strong systemic inflammatory response had elevated tissue expression of proinflammatory cytokines interleukin (IL)-1 $\beta$, tumor necrosis factor- $\alpha$, and IL- $6^{13}$. On the other hand, Weyand, et al demonstrated that temporal artery biopsy specimens from GCA patients with visual ischemic complications express high amounts of interferon (IFN)- $\gamma$ mRNA $^{14}$. This cytokine plays an important role in the process of luminal obstruction and in the development of ischemic manifestations of GCA. According to these authors, IFN- $\gamma$ may dictate the functional properties of other cell populations in the vascular infiltrates and guide the response-to-injury reaction of the artery ${ }^{15}$.

As pointed out by Saleh, et al, genetic variations may also modulate the risk of visual ischemic complications in patients with $\mathrm{GCA}^{5}$. A large-scale genetic analysis has recently confirmed a strong contribution of the HLA-class II region

Personal non-commercial use only. The Journal of Rheumatology Copyright (C) 2016 . All rights reserved. 
to GCA susceptibility ${ }^{16}$. Interestingly, an association of HLA-class II-DRB $1 * 04$ with visual complications was reported $^{2,17}$. Genetic variants associated with high IFN- $\gamma$ expression ${ }^{18}$ and others associated with lower expression of the angiogenic vascular endothelial growth factor ${ }^{19}$ have also been reported to predispose to severe ischemic complications in patients with GCA.

Another issue that deserves further investigation is whether the frequency of visual ischemic manifestations, and therefore the visual outcome, is different in patients with biopsy-proven GCA from that observed in biopsy-negative patients diagnosed with GCA according to well-established classification criteria. A population-based study suggested that the prevalence of severe ischemic complications, including permanent visual loss, may be reduced in biopsy-negative patients when compared with those in whom the diagnosis was confirmed by a positive temporal artery biopsy ${ }^{20}$.

A final issue is the importance of early onset of therapy to reduce the risk of visual loss in GCA. High-dose corticosteroid therapy must be given to patients presenting with amaurosis fugax because an episode of transient visual loss constitutes the best clinical predictor of irreversible visual $\operatorname{loss}^{2}$. Nevertheless, regardless of the presence of alarm signals, prompt treatment with at least $40 \mathrm{mg} /$ prednisone/day should be prescribed to patients in whom GCA is suspected. A delay in the onset of treatment may have ominous consequences because few patients treated with corticosteroids, either orally or with high-dose methylprednisolone pulses, recover vision once that visual loss is established ${ }^{2}$.

The study conducted by Saleh, et al supports the claim that, although there is decline in the frequency of visual ischemic complications of GCA, these complications still constitute the leading cause of disability in patients with this vasculitis. The role of HTN prior to the onset of GCA, the degree of inflammatory burden at the time of diagnosis, and the genetic component in the risk of permanent visual loss in patients with GCA warrant further investigation.

\section{MIGUEL A. GONZALEZ-GAY, MD, PhD,}

Professor of Medicine, University of Cantabria,

Director Epidemiology, Genetics and Atherosclerosis

Research Group on Systemic Inflammatory Diseases, IDIVAL;

Rheumatology Division, Hospital Universitario Marqués de Valdecilla, Santander, Spain;

\section{SANTOS CASTAÑNDA, $\mathrm{MD}, \mathrm{PhD}$,}

Rheumatology Division, Hospital de la Princesa,

IIS-IP, Universidad Autónoma,

Madrid, Spain;

\section{JAVIER LLORCA, MD, PhD,}

Professor of Epidemiology and Computational Biology,

School of Medicine, University of Cantabria,

CIBER Epidemiología y Salud Pública (CIBERESP), IDIVAL, Santander, Spain.

Address correspondence to Prof. M.A. González-Gay, Rheumatology Division, Hospital Universitario Marqués de Valdecilla,

c/ Avenida de Valdecilla s/n, 39008, Santander, Spain.

E-mail: miguelaggay@hotmail.com

\section{REFERENCES}

1. Gonzalez-Gay MA, Vazquez-Rodriguez TR, Lopez-Diaz MJ, Miranda-Filloy JA, Gonzalez-Juanatey C, Martin J, et al. Epidemiology of giant cell arteritis and polymyalgia rheumatica. Arthritis Rheum 2009;61:1454-61.

2. González-Gay MA, García-Porrúa C, Llorca J, Hajeer AH, Brañas F, Dababneh A, et al. Visual manifestations of giant cell arteritis. Trends and clinical spectrum in 161 patients. Medicine 2000;79:283-92.

3. Hayreh SS, Podhajsky PA, Zimmerman B. Ocular manifestations of giant cell arteritis. Am J Ophthalmol 1998;125:509-20.

4. Keltner JL. Giant-cell arteritis. Signs and symptoms. Ophthalmology 1982;89:1101-10.

5. Saleh M, Turesson C, Englund M, Merkel PA, Mohammad AJ Visual complications in patients with biopsy-proven giant cell arteritis - a population-based study. J Rheumatol 2016;43:1559-65.

6. Salvarani C, Cimino L, Macchioni P, Consonni D, Cantini F, Bajocchi G, et al. Risk factors for visual loss in an Italian population-based cohort of patients with giant cell arteritis. Arthritis Rheum 2005;53:293-7.

7. Gonzalez-Gay MA, Miranda-Filloy JA, Lopez-Diaz MJ, Perez-Alvarez R, Gonzalez-Juanatey C, Sanchez-Andrade A, et al Giant cell arteritis in northwestern Spain: a 25-year epidemiologic study. Medicine 2007;86:61-8.

8. Gonzalez-Gay MA, Piñeiro A, Gomez-Gigirey A, Garcia-Porrua C, Pego-Reigosa R, Dierssen-Sotos T, et al. Influence of traditional risk factors of atherosclerosis in the development of severe ischemic complications in giant cell arteritis. Medicine 2004;83:342-7.

9. Gonzalez-Gay MA, Lopez-Diaz MJ, Barros S, Garcia-Porrua C, Sanchez-Andrade A, Paz-Carreira J, et al. Giant cell arteritis: laboratory tests at the time of diagnosis in a series of 240 patients. Medicine 2005;84:277-90

10. Lopez-Diaz MJ, Llorca J, Gonzalez-Juanatey C, Peña-Sagredo JL, Martin J, Gonzalez-Gay MA. The erythrocyte sedimentation rate is associated with the development of visual complications in biopsy-proven giant cell arteritis. Semin Arthritis Rheum 2008;38:116-23.

11. Muratore F, Boiardi L, Cavazza A, Aldigeri R, Pipitone N, Restuccia $\mathrm{G}$, et al. Correlations between histopathological findings and clinical manifestations in biopsy-proven giant cell arteritis. J Autoimmun 2016;69:94-101

12. Cid MC, Font C, Oristrell J, de la Sierra A, Coll-Vinent B, Lopez-Soto A, et al. Association between strong inflammatory response and low risk of developing visual loss and other cranial ischemic complications in giant cell (temporal) arteritis. Arthritis Rheum 1998;41:26-32.

13. Cid MC, Hernandez-Rodriguez J, Esteban MJ, Cebrian M, Gho YS, Font $\mathrm{C}$, et al. Tissue and serum angiogenic activity is associated with low prevalence of ischemic complications in patients with giant-cell arteritis. Circulation 2002;106:1664-71.

14. Weyand CM, Tetzlaff N, Bjornsson J, Brack A, Younge B, Goronzy JJ. Disease patterns and tissue cytokine profiles in giant cell arteritis. Arthritis Rheum 1997;40:19-26.

15. Weyand CM, Ma-Krupa W, Goronzy JJ. Immunopathways in giant cell arteritis and polymyalgia rheumatica. Autoimmun Rev 2004;3:46-53.

16. Carmona FD, Mackie SL, Martín JE, Taylor JC, Vaglio A, Eyre S, et al. A large-scale genetic analysis reveals a strong contribution of the HLA class II region to giant cell arteritis susceptibility. Am J Hum Genet 2015;96:565-80.

17. González-Gay MA, Amoli MM, Garcia-Porrua C, Ollier WE. Genetic markers of disease susceptibility and severity in giant cell arteritis and polymyalgia rheumatica. Semin Arthritis Rheum 2003;33:38-48.

18. Gonzalez-Gay MA, Hajeer AH, Dababneh A, Garcia-Porrua C, 
Amoli MM, Llorca J, et al. Interferon-gamma gene microsatellite polymorphisms in patients with biopsy-proven giant cell arteritis and isolated polymyalgia rheumatica. Clin Exp Rheumatol 2004;6 Suppl 36:S18-20.

19. Rueda B, Lopez-Nevot MA, Lopez-Diaz MJ, Garcia-Porrua C, Martín J, Gonzalez-Gay MA. A functional variant of vascular endothelial growth factor is associated with severe ischemic complications in giant cell arteritis. J Rheumatol 2005;32:1737-41.
20. Gonzalez-Gay MA, Garcia-Porrua C, Llorca J, Gonzalez-Louzao C, Rodriguez-Ledo P. Biopsy-negative giant cell arteritis: clinical spectrum and predictive factors for positive temporal artery biopsy. Semin Arthritis Rheum 2001;30:249-56.

J Rheumatol 2016;43:1458-61; doi:10.3899/jrheum.160466 